\title{
Urgences
}

\section{E muet bruissements}

\section{Rose-Hélène Tremblay}

Numéro 1, 2e trimestre 1981

URI : https://id.erudit.org/iderudit/025010ar

DOI : https://doi.org/10.7202/025010ar

Aller au sommaire du numéro

Éditeur(s)

Urgences

ISSN

0226-9554 (imprimé)

1927-3924 (numérique)

Découvrir la revue

Citer ce document

Tremblay, R.-H. (1981). E muet bruissements. Urgences, (1), 55-59.

https://doi.org/10.7202/025010ar

Ce document est protégé par la loi sur le droit d'auteur. L'utilisation des services d'Érudit (y compris la reproduction) est assujettie à sa politique d'utilisation que vous pouvez consulter en ligne.

https://apropos.erudit.org/fr/usagers/politique-dutilisation/
Cet article est diffusé et préservé par Érudit.

Érudit est un consortium interuniversitaire sans but lucratif composé de l’Université de Montréal, l'Université Laval et l'Université du Québec à Montréal. Il a pour mission la promotion et la valorisation de la recherche. https://www.erudit.org/fr/ 
ROSE-HELENE TREMBLAY

e muet bruissements 
e muet bruissements

Deux vieillards s'aimaient dans l'herbe en pleurant comme des enfants

Le soir était tombé depuis longtemps. La fête avait pétillé dans les yeux du primitif. Et moi, restée à la cave, je grattais les murs et mangeais des mousses blanches, un filet de lumière entre les dents. Puis j'avais gravi les marches vermoulues du temps et revu le même soleil qu'autrefois... avec ces mêmes yeux noirs, tubercules de la nuit.

Il fallait revenir payer ses dettes. Il me fallait puiser dans une coupe d'airain, accoudée à la margelle des intempéries, des eaux aux étranges reflets à J'étrange ivresse. Valait mieux être seule pour s'y baigner, valait mieux s'y noyer en secret...

Deux enfants s'aimaient dans l'herbe en pleurant comme des vieillards

Nous devrions payer en monnaie d'or le poids de nos crimes. Tout un troupeau de bêtes dégénérées nous suivait à la trace, des lambeaux de vie. Une buée s'élève douce, douce... n'avance pas trop près... j'ai peur du feu, des brâlures et des regards. J'ai peur des frontières de brumes déchirées.

Un mur de songes clôture mon jardin. J'y ai planté du lierre, des vignes et des rosiers sauvages. Ma tourelle est au faîte du château creusée dans une pierre noire. Les oiseaux du désespoir migrateur y sont venus nicher. Ils vont repartir bientôt. J'irai sur le faîte respirer la rose des vents. 
Lne enfant est au seuil

assise dans la verdure

Sa tête est ouverte comme un pétale déchiré. Elle cherche dans un petit vase la clé de sa serrure. La serrure est si grande qu'elle décide d'y passer tout entière. Sa route la mène en un palais de marbre. Il y a dans un coin les restes d'un festin. Un chien caresse ses os tendrement... l'enfant s'approche aussitôt et se glisse dans l'eau. La vague l'inonde et l'enfant coule au plus profond du temps. Elle rencontre un bélier noir, une grande broche en son centre comme une corne dérisoire. Le bélier n'a plus de mots pour parler de sa vie et sa laine est devenue un tricot que porte la nuit pour se réchauffer... et l'enfant aborde le mouton noir.

- J'ai le souff́le léger et la parole amère chante qui bêle. Sa voix cassée ébranle... La nuit est trop noỉre. L'enfant a peur. Une étoile passe et s'accroche à son pied.

- Enfin, je suis à l'abri de la lumière... et l'enfant se referme entre les pétales du sommeil.

Soudainement le bélier noir se métamorphose en une brebis galeuse. A son front scintille une corne magique qui éclaire ses plaies. La brebis s'approche, déchire la cachette de l'enfant. Son rire inonde les pages de larmes.

- Ne pleure plus bêle la brebis accoudée au tronc d'un gros arbre mort. Il y a dans le coeur de cet arbre une petite graine verte. La graine ne peut germer que dans les jardins de l'enfance. Si tu oses pénétrer dans le ventre de la mort tu auras un trésor dont le pouvoir sera connu de toi seule.

La petite brebis disparut lentement dans un murmure...

Jirai...

Et l'enfant pénétra dans le ventre de l'arbre. Il y avait des plumes noires accrochées au flanc de la mort. Pas un souffle. pas une brise. L'enfant descendit les marches du grand escalier en colimaçon. Chaque marche était une chute et le froid finit par paralyser ses mouvements à la dernière marche... elle vit un sous-bois sombre et le scintillement de douces lumières peut-être lucioles, peut-être étoiles filantes et le silence resserrait comme un secret. 
Apparut alors la petite brebis galeuse et son visage avait les rides de l'âge. Elle se colla aussitôt à l'enfant et lui fit un manteau de laine noire. La douce chaleur du mouvement coula à nouveau.

Une petite brise se leva. Le soir était en pierre. L'enfant sourit. Une pomme rouge tomba du ciel. Elle la recueillit dans sa main et la mangea, de faim... A la dernière bouchée, un pépin tomba noir sur sa corne de brebis, libérant le jour. Le soleil était chaud et une légère brume de chaleur exsudant des champs la souleva... Ne pouvant plus regarder en bas, le regard de ses habitudes s'éteignit et le petit pépin au bout de sa corne l'ouvrit aux images du ciel... Rien n'était plus pareil. Les couleurs étaient peut-être des sons et les ombres d'autrefois des reflets... Elle marchait sur deux jambes et bêlait quelquefois dans le matin blềme.

Il y eut un soir un arc-en-ciel; l'enfant voulut y boire pour abreuver son regard. S'approcha d'un peu trop près des couleurs de la tendresse et bascula dans les tièdes vapeurs colorées. Une grande louve blanche l'attendait, gardienne du mystère de l'are.

- Enfant, je te retiens prisonnière.

De l'instant, l'enfant fut envốtée... elle oublia les marches de la mort, les efforts, la douleur des refus, les miettes de la contradiction et les dards remplis de venins. La louve lui avait mis deux oeillères roses, un mors de vague bleue et son attelage était un fil de cheveux d'or. L'enfant s'avançait du seul souffle de la louve, dans l'oubli. Elle hululait à la tombée du jour dans un murmure presqu'inaudible.

C'est ainsi qu'un beau soir elles arrivèrent aux confins de l'arc.

- Je n'ai de pouvoir que dans le prisme lumineux, dit la grande louve et elle lui indiqua la route d'un puits noir. L'enfant y plongea aussitôt. Un grand frisson noir l'attendait reconvert d'écailles argentées.

- J'ai mission de te mener là où tu dois germer... 
L'enfant s'agrippa dès lors aux nageoires de la transparence et ils filèrent jusqu'à la berge où l'enfant seule s'endormit dans un lit de gros cailloux blancs. L'aube se leva sur les pierres chaudes et odorantes. Une boulangère apparut de la grandeur d'un arbre. De grosses gouttes ruisselaient de son front rouge. Une goutte tomba sur la graine de l'enfant qui se fendit. Une petite racine blanche en sortit nouant l'enfant à la terre et deux petites feuilles vertes comme des ailes la déplièrent dans le soir couchant. Petit papillon ancré...

Et le jour enfin était au présent...

Deux vieillards tressaient le foin de la mer en priant

comme des enfants

Comme toujours, le fils du roi s'en va chassant et Salomée l'attend encore en dansant... Il y aura peut-être un souper sanglant...

- Une tête s'il vous plaît, sur le plat...

S'il faut osciller entre soi et l'autre, je m'exilerai encore...

Assise sur la tranchée, je me regarderai me battre, tous pores ouverts...

Deux vieillards s'aimeront

s'aimaient

se sont aimés peut-être

dans les grands flots verts

comme des enfants

dans la verdure 